\title{
A QUANTITATIVE APPROACH TO NEMATODE LUNGWORM BURDENS IN GOATS
}

\author{
BERRAG B.* , BOULJIHAD M.** \& CABARET J.****
}

\begin{abstract}
Summary :
Nematode lungworm burdens are difficult to evaluate at necropsy. The recovery of protostrongylid worms was achieved by three different post-mortem quantification techniques. Perfusion of the lungs under watertap pressure was successful in washing out Protostrongylus rufescens and Cystocaulus ocreatus but not Muellerius capillaris and Neostrongylus. Incubation of the lungs by pepsin and hydrochloric acid solution prior to perfusion helped to recover trapped Muellerius and Neostrongylus. Worm nodules were classified into type $A, B$ and $C$, on increasing calcification process. Examination of these nodules showed that 75 to $80 \%$ of type $A$ and $B$ contained a parasite. Worms recovered by perfusion added to the sum of type $A$ and $B$ nodules were used to construct formula for quantifying the total lungworm burdens from naturally infected goat lungs and may provide a reasonable basis for assessing anthelmintic efficacy.
\end{abstract}

KEY WORDS : nematode, lungworm, goat, Protostrongylids, intensity.

\section{INTRODUCTION}

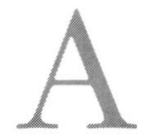
quantification of lungworm burdens in infected small ruminants is difficult. Adult Dictyocaulus filaria and Protostrongylus sp. can be recovered easily at necropsy. However, the harvest of Cystocaulus ocreatus from bronchioles and Muellerius capillaris and Neostrongylus linearis from the lung alveola is much more difficult. Adult Dictyocaulus were generally removed by a modified Baermann technique (Jarett \& Sharp, 1963; Michel, 1954). Later Inderbitzen (1976) described a method of perfusing bovine lungs to remove Dictyocaulus viviparus by injecting Tyrode's solution under pressure through the pulmonary artery with the fluid emerging from the trachea being examined for lungworms after sedimentation.

\footnotetext{
* Département de Parasitologie et Maladies Parasitaires, Institut Agronomique et Vétérinaire Hassan II, BP 6202, Rabat-Instituts, 10100 Rabat, Morocco

** Département d'Histologie et Anatomie Pathologique, Institut Agronomique et Vétérinaire Hassan II, BP 6202, Rabat-Instituts, 10100 Rabat, Morocco.

*** INRA, Station de Pathologie aviaire et de Parasitologie, Unité d'Écologie des Parasites, F-37380 Nouzilly.
}

Résumé : EstIMATION QUANTITATIVE DE L'INFESTATION DES CHÈvRES PAR LES NÉMATODES PULMONAIRES

L'estimation de l'infestation par les nématodes pulmonaires est délicate à l'autopsie. La récolte des protostrongles a été réalisée au moyen de trois techniques. La perfusion sous pression des poumons a été satisfaisante pour la récupération de Protostrongylus rufescens et Cystocaulus ocreatus et très insuffisante pour Muellerius capillaris et Neostrongylus linearis. La perfusion, précédée d'une digestion pepsique, améliore la récolte de M. capillaris et de N. linearis. Les nodules sur le poumon ont été classés A, B, C en raison de leur calcification croissante et sont examinés pour la présence de parasites. Des protostrongles sont rencontrés dans $75 \%$ des nodules $A$ et $80 \%$ des nodules $B$. L'utilisation des résultats obtenus à partir de la perfusion et de la dissection des nodules permettent de quantifier l'intensité du parasitisme dans les poumons. Cela devrait fournir une base raisonnable pour l'appréciation de l'efficacité des antihelminthiques.

MOTS CLÉS : nématodes pulmonaires, chèvre, Protostrongles, intensité.

Oakley (1980) found Inderbitzen's method efficient but the cannulation and the use of Tyrode's solution at high pressure, requiring a complicated apparatus to ensure delivery of this solution, make the method too complex, time consuming and expensive for routine laboratory use. He therefore proposed a modified method of lung perfusion using tap water instead of Tyrode's solution and that with practice, one set of lungs could be perfused in $20 \mathrm{~min}$. Triki-Yamani (1983) attempted to alter the modified Inderbitzen's method to recover protostrongylids from naturally infected sheep. This procedure consisted of prior injection of pepsin solution (chloride solution: $5 \mathrm{~g}$ pepsin, $5 \mathrm{ml}$ $\mathrm{HCl}, 100 \mathrm{ml}$ water) into the trachea and incubation at $37{ }^{\circ} \mathrm{C}$ for two hours followed by perfusion of the lung with tap water. According to this author, the peptic digestion helped to release $M$. capillaris and $N$. linearis trapped in the parenchyma and therefore it enhanced the recovery of protostrongylids after perfusion of the lungs.

The assessment of protostrongylid burdens and the anthelmintic efficacy against small lungworms drugs usually are based solely on the number of larvae recovered from faeces and lung tissue by baermann tech- 
nique, and adult worms harvested by dissection of the airways (Cabaret, 1980 a; Cabaret et al., 1980; Dakkak et al., 1986; Dakkak et al., 1979; Pandey, 1980; Thomas et al., 1970). In such situations, adult M. capillaris, $N$. linearis and $C$. ocreatus could be omitted and therefore worm burdens might be underestimated.

In view of the high incidence of lungworm infections of small ruminants (and particularly goats) in many parts of the world, and the wide range of anthelmintic drugs used by farmers, it is clearly needed to improve necropsy techniques to achieve a quantitative approach of lungworm burdens in the course of epidemiological investigations and the production of test model for the assessment of anthelmintic efficacy against small lungworms (particularly M. capillaris and N. linearis).

\section{MATERIALS AND METHODS}

All the goats studied here were naturally infected and originated from Morocco.

\section{RECOVERY OF WORMS BY DISSECTION OF NODULES}

A total of 1,495 nodular lesions from goat lungs collected in Rabat (Morocco) were randomly selected for dissection and examination of their contents. Nodules were classified into three types A, B and C according to Sauerlander (1988):

- type A nodules are small dark spots with red centers, hemorrhagic and not calcified lesions,

- type B nodules are reddish to yellowish and slightly calcified granulomatous lesions,

- type C nodules are whitish, glassy and strongly calcified granulomatous lesions.

The pleura was first peeled and different type of worm nodules were removed into Petri dishes and dissected by using needles under stereomicroscope at $\times 12$ magnification. These nodules were mostly subpleural in location.

\section{RECOVERY OF WORMS BY PERFUSION OF LUNGS}

A total of 476 goat lungs collected from rural abattoirs of Rabat area over two year period 1991-1992 were used in this study. The lungworms were recovered by using a modified Inderbitzen's method described by Oakley (1980), with a little modification which consisted to the delivery of water under the tapwater pressure instead of the use of pressure apparatus. The right ventricle wall was opened by a stab wound and a rubber tubing was fed through this incision until the pulmonary artery and fixed in situ by ligation. The free end of the rubber tube was attached to a tapwater. The free end of the trachea was placed on the upper surface of nylon mesh with aperture of about $45 \mu \mathrm{m}$, which rested on a bowl marked at the five liters volume level. Tap water was then allowed to flow at medium pressure into the lungs via the pulmonary artery until five liters of water had flowed out of the trachea and through the sieve into the bowl. The residues remaining on the sieve were washed into Petri dishes and searched for lungworms using stereomicroscope at $\times 12$ magnification.

\section{RECOVERY OF WORMS BY PERFUSION OF LUNGS PRECEDED BY PEPTIC DIGESTION}

A total of 13 goat lungs with nodular lesions from Rabat were used to recover worms by prior peptic digestion followed by perfusion of the lungs. The first lung was processed by perfusing the right lung and by the use of the peptic digestion method on the left lung. The second pair of lungs were processed in the same way except that perfusion was used on the left lung and the peptic digestion on the right lung and so on alternatively until lungs from 13 goats had been processed. The unilateral lung perfusion was as described for the bilateral lung perfusion except that the rubber tubing introduced into the pulmonary artery was guided past the bifurcation into either right or left pulmonary arteries and fixed in situ by ligation. The lumen of the pulmonary artery and the bronchi of the other side were then closed by ligation. The catheterized lung was then perfused with tapwater. After this perfusion, the other lung which remained collapsed was filled with one liter of water solution containing $5 \mathrm{mg}$ of pepsin and $5 \mathrm{ml}$ of hydrochloric acid, through the trachea. The aperture of the trachea was blocked up by a cork and placed into the incubator at $37^{\circ} \mathrm{C}$ for two hours as described by Triki-Yamani (1983). The incubation was followed by perfusion with tapwater and the residues were searched for lungworms as described above.

\section{STATISTICAL ANALYSIS}

The data did not follow a Gaussian distribution and a nonparametric test was prefered. The Wilcoxon matched-pairs signed-ranks test was used to compare the efficacy of the three techniques of worms' recovery.

\section{RESULTS}

\section{DisSECTION OF WORM NODULES}

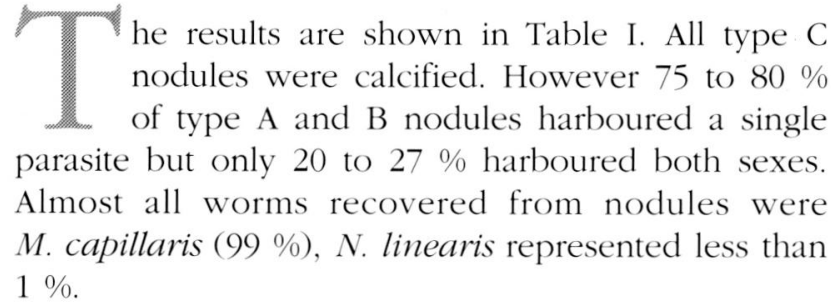




\begin{tabular}{cccc}
\hline $\begin{array}{c}\text { No. of } \\
\text { nodules } \\
\text { examined }\end{array}$ & $\begin{array}{c}\text { Norcentage } \\
\text { of nodules } \\
\text { containing } \\
\text { worms }\end{array}$ & $\begin{array}{c}\text { No. and } \\
\text { percentage } \\
\text { of nodules } \\
\text { containing } \\
\text { only one sex }\end{array}$ & $\begin{array}{c}\text { No. and } \\
\text { percentage } \\
\text { of nodules } \\
\text { containing } \\
\text { both sexces }\end{array}$ \\
\hline $\begin{array}{c}\text { Type A } \\
(n=500)\end{array}$ & 375 & 300 & 75 \\
\hline $\begin{array}{c}\text { Type B } \\
(n=600)\end{array}$ & $85 \%$ & $80 \%$ & $20 \%$ \\
\hline $\begin{array}{c}\text { Type C } \\
(n=395)\end{array}$ & 0 & 360 & 128 \\
\hline
\end{tabular}

Table I. - Dissection of nodular lesions of increased calcification - type A, B, C in lungs from goats naturally infected and the records of worms (Muellerius capillaris and Neostrongylus linearis) they contained.

\section{RECOVERY OF LUNGWORMS BY PERFUSION} OF LUNGS

The recovery of worms using perfusion technique was assessed in 476 lungs carrying different type of lesions induced by protostrongylids. From a random sample of 692 lobular lesions, the following species were found on identification of 3,200 first-stage larvae: M. capillaris $(51 \%)$, C. ocreatus (28\%) and Protostrongylus rufescens (22\%). A proportion of $84 \%$ of lungs with lobular lesions and $65 \%$ of lungs with both nodular and lobular lesions yielded parasites. By contrast, lungworms were obtained from only $14 \%$ of lungs with only nodular lesions.

\section{PROTOSTRONGYLID BURDENS RECOVERED \\ FROM LUNGS USING PEPTIC DIGESTION AND PERFUSION METHOD (Table II)}

A mean of 2.2 worms per pair of lungs with nodular lesions was recovered by using perfusion method. The peptic digestion method followed by perfusion gave a mean recovery of 22 worms per pair of lungs. The recovery of protostrongylids by the perfusion technique was $9.1 \%$ and by peptic digestion $90.9 \%$ if we assess that $100 \%$ recovery corresponded to the added results of perfusion and peptic digestion. The results are statistically different (Wilcoxon test; $p=0.007)$.

\section{ESTIMATION OF M. CAPILLARIS \\ AND N. LINEARIS BURDENS}

The number of nodules from the same 13 goat lungs are reported in Table II. Since $M$. capillaris (and $N$. linearis to a very limited extent in our sample) is found to be the cause of nodule formation and the perfusion technique failed to recover this species from the parenchyma of lungs carrying nodular lesions, it is attempted to estimate their number by using the formula $(x A+x B) \times 0.75$ where: $(x A+x B)=$ sum of the number of worm nodules type $\mathrm{A}$ and $\mathrm{B}, 0.75$ $=$ minimum percentage of nodules type $\mathrm{A}$ and $\mathrm{B}$ containing parasites (males or females). An average of 138 worms per pair of lungs were estimated by using the formula.

\section{DISCUSSION}

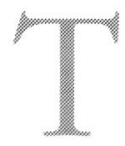

he examination of worm nodules showed a number of interesting features. All the type C nodules contained disintegrating worms and were completely calcified. However, the majority ( 75 to $80 \%)$ of type A and B nodules contained but a single worm and only few (20 to $25 \%$ ) contained both sexes. The explanation lies in the site and the mode of development of $M$. capillaris and $N$. linearis whereby many worms become isolated in their own nodules. Female worms so isolated cannot produce fertile eggs and first stage larvae. A point of practical significance which emerges from the present observations is that the faecal examinations may have limited meaning. Not only are faecal examinations used as an aid for diagnosis, but also as a means of assessing the degree of infection and as an index of the efficacy of new anthelmintic drugs. At all times, caution must be exercised in interpreting the results of faecal examinations and it is particularly important when dealing with $M$. capillaris.

The different species of protostrongylids in goats cause various pathological changes in the lungs which can at least partly be considered type-specific of the parasite. The nodular lesions are related to M. capillaris and $N$. linearis while the lobular lesions are mainly due to C. ocreatus and P. rufescens (Berrag, 1993). Because of their location in the airways, $P$. rufescens and $C$. ocreatus are successfully washed out by perfusing the lungs under watertap pressure, but not $M$. capillaris and $N$. linearis which are encapsulated within the lung tissue (Rose, 1958). The type of lesions induced by $M$. capillaris can be somehow different in other parts of the world, as observed by one of us in Frenchdairy-goats: lobular lesions are very frequent although the infection remains moderate compared with goats in Moroccan conditions.

Inflation of the lungs by pepsin hydrochloric acid solution prior to perfusion proved to be an acceptable method for recovering an appreciable number of protostrongylid worms including trapped $M$. capillaris and $N$. linearis from goat lungs. However, the use of pepsin solution and the need of a large apparatus to perform incubation at $37^{\circ} \mathrm{C}$ make the method too complex, time consuming and expensive for routine laboratory use. 


\begin{tabular}{|c|c|c|c|c|}
\hline Lungs no. & $\begin{array}{c}\text { Perfusion } \\
\text { (Right or left lung) } \\
\text { (Cystocaulus ocreatus } \\
\text { and Protostrongylus rufescens) }\end{array}$ & $\begin{array}{c}\text { Peptic digestion } \\
\text { (corresponding right } \\
\text { or left lung) } \\
\text { (Cystocaulus ocreatus and } \\
\text { Protostrongylys rufescens) }\end{array}$ & $\begin{array}{c}\text { Number of } \\
\text { nodules }(\mathrm{N}) \\
\text { type } \mathrm{A}+\mathrm{B} \\
\text { (Muellerius capillaris) }\end{array}$ & $\begin{array}{c}\text { Formula } \\
\mathrm{N} \times 0.75 \\
\text { to assess number } \\
\text { of Muellerius capillaris }\end{array}$ \\
\hline 1 & 2 & 15 & 123 & 92 \\
\hline 2 & 0 & 6 & 54 & 41 \\
\hline 3 & 0 & 7 & 27 & 20 \\
\hline 4 & 0 & 5 & 23 & 17 \\
\hline 5 & 9 & 25 & 261 & 196 \\
\hline 6 & 0 & 2 & 45 & 34 \\
\hline 7 & 0 & 3 & 30 & 23 \\
\hline 8 & 7 & 65 & 422 & 317 \\
\hline 9 & 11 & 120 & 818 & 613 \\
\hline 10 & 0 & 11 & 87 & 65 \\
\hline 11 & 0 & 9 & 49 & 37 \\
\hline 12 & 0 & 13 & 100 & 75 \\
\hline 13 & 0 & 10 & 46 & 35 \\
\hline Mean & 2.2 & 22 & 160 & 138 \\
\hline SD & 1.7 & 11 & 68 & 64 \\
\hline
\end{tabular}

Table II. - Lungworm burdens recovered from 13 naturally infected goat lungs by three different methods.

Evaluation of the perfusion technique, peptic digestion and the use of the formula $(\mathrm{xA}+\mathrm{xB}) \times 0.75$ to estimate $M$. capillaris and $N$. linearis burdens showed that the formula gives a good indication of the worms burdens despite the omission of small number of nodules distributed inside the parenchyma. It is probable that the peptic digestion method prior to perfusing the lungs is not critical if the objective is recovery of lungworms for diagnostic purposes or assessment of the degree of infection. In these circumstances, the peptic digestion could be omitted. It emerges from the present work that it could be acceptable in practice for quantifying lungworm burdens including Dictyocaulus and protostrongylid species from small ruminant lungs, to proceed as follows:

1) counting and differentiation of worm nodules in the lungs into type $\mathrm{A}, \mathrm{B}$ and $\mathrm{C}$,

2) dissection of large numbers of worm nodules in order to assess the percentage of nodules containing $M$. capillaris and $N$. linearis,

3) perfusion of the lungs to recover $P$. rufescens, C. ocreatus and Dictyocaulus filaria located in the airways.

The data obtained from these investigations might be combined in the following formula:

$\mathrm{TWB}=\mathrm{xw} \cdot \mathrm{p}+(\mathrm{xA}+\mathrm{xB}) \times 0.75$

where $:$ TWB $=$ Total Worm burdens, $x$ w.p $=$ average number of worms recovered by perfusion of the lungs, $(\mathrm{xA}+\mathrm{xB})=$ sum of the nodules type $\mathrm{A}$ and $\mathrm{B}$, $0.75=$ minimal percentage of nodules type $\mathrm{A}$ and $\mathrm{B}$ containing parasites. This formula may provide a reasonable basis for assessing lungworm burdens and anthelmintic efficacy against protostrongylids.

\section{ACKNOWLEDGEMENTS}

S incere appreciation is expressed to the International Foundation For Science (IFS, Stokholm) for providing the financial support to conduct this study.

\section{REFERENCES}

Berrag B. Aspects of lungworm infections of goats in Morocco. PhD Thesis. Institut Agronomique et Vétérinaire Hassan II, Rabat, 1993, Morocco.

CABARET J., DaKKaK A. \& Bahaida B. On some factors influencing the output of the larvae of protostrongylids of sheep in natural conditions. Veterinary Quarterly, 1980 a, 2, 115120 .

Cabaret J., DakKak A. \& Bahaida B. A technic of the evaluation of the number of protostrongylid first stage larvae in sheep faeces. British Veterinary Journal, 1980 b, 136, 296-298.

DakKak A, Cabaret J. \& Ouhelli H. Efficacité comparée du fenbendazole et du tétramisole sur les helminthoses ovines au Maroc. I. Protostrongylidés et Dictyocaulus filaria. Recueil de Médecine Vétérinaire, 1979, 155, 703-711.

DakKak A., Robin B. \& Kachan M. Efficacité de l'ivermectine dans le traitement des bronchopneumonies vermineuses, des strongles digestifs et de l'œestrose du mouton. Revue de Médecine Vétérinaire, 1986, 137, 781-787.

InDERBITzIN F. Experimentell erzeugte Entwicklungshemmung von Dictyocaulus viviparus des Rindes. PhD thesis, University of Zurich, 1976, Switzerland.

JARRET W.F.H. \& SHARP N.C.C. Vaccination against parasitic diseases: reactions in vaccinated and immune hosts in Dic- 
tyocaulus viviparus infection. Journal of Parasitology, 1963, 49, 177-189.

Michel J.F. Pulmonary oedema in sheep caused by immature lungworms. Veterinary Record, 1954, 66, 460.

OAKLEY G.A. The recovery of Dictyocaulus viviparus from bovine lungs by lung perfusion: a modification of Inderbitzen's method. Research in Veterinary Science, 1980, 29, 395-396.

PANDEY V.S. Effect of tetramisole on protostrongylid lungworms of sheep. Annales de la Société Belge de Médecine Tropicale, 1980, 60, 103-106.

Rose J.H. Site of development of the lungworm Muellerius capillaris in experimentally infected lambs. Journal of Comparative Pathology, 1958, 68, 359-362.

SAuerlander R. Experimental infection of sheep and goats with Muellerius capillaris (Protostrongylidae, Nematoda). Journal of Veterinary Medicine, B., 1988, 35, 525-548.

Thomas R.J., Nunns V.J. \& Boag B. The incidence of lungworm infection in sheep in North East of England. Veterinary Record, 1970, 87, 70-75.

Triki-Yamani R. Contribution à l'étude des strongyloses respiratoires des petits ruminants : Numérations parasitaires et topographie des lésions. Mémoire Maître ès-Sciences Vétérinaire. École Vétérinaire de Toulouse, 1983, France.

Reçu le 27 mars 1996 Accepté le 24 mai 1996 